\title{
LA INFORMACIÓN PROVENIENTE DE LAS REDES SOCIALES COMO MEDIO TECNOLÓGICO DE PRUEBA*
}

\author{
Julien Alzamora', Sophie Araúz ${ }^{I I}$, Susana Averza ${ }^{I I I}$, Manuel Barrías ${ }^{I V}$, \\ Lilia BonomeV ${ }^{V}$ Denis González ${ }^{V I}$, Lidia Karina Mercado ${ }^{V I I}$, \\ Daniel Musmanno ${ }^{\text {VIII }}$, Dayana Sumosa ${ }^{I X}$, Noel Mitzaida ${ }^{X}$
}

\begin{abstract}
RESUMEN
El trabajo propuesto tiene como fin conocer de qué forma se dan las pruebas emanadas de las redes sociales, cuáles son sus medios de obtención y de qué manera pueden ser admitidas y autenticadas en un proceso judicial, además de entender el valor que constituyen estas
\end{abstract}

Fecha Recibido: abril 11 de 2014 • Fecha Aceptado: julio 14 de 2014

* Este artículo es una versión inédita del trabajo que surge del Semillero de Investigación creado en la Facultad de Derecho y Ciencias Políticas de la Universidad de Panamá. Se presentó los días 11, 12 y 13 de septiembre de 2013 en la ciudad de Medellín, Colombia, por Lidia Karina Mercado en el marco del XXXIV Congreso Colombiano de Derecho Procesal, obteniendo el Primer Premio en el XIII Concurso Internacional para Estudiantes de Derecho Nivel Pregrado. El semillero de Derecho Procesal estuvo formado por Lilia Bonome, Sophie Arauz Cornejo, Lidia Karina Mercado, Manuel Barrías, Mitzaida Noel, Dayana Sumosa, Denis González, Jullien Alzamora, Daniel Musmano y Susana Averza. Fueron Directores de este trabajo de Investigación el Dr. Candelario Santana, Director del departamento de Derecho Procesal de la Facultad de Derecho y Ciencias Políticas de la Universidad de Panamá, Catedrático de Derecho Procesal y David Alexander Bernal, Abogado, egresado de la Universidad de Panamá con la tesis "La condición de Prisionero de Guerra en el caso de Manuel Antonio Noriega". Fue asesor jurídico en la Comisión para la Reforma a la Constitución de Panamá en el 2011, Activista en DDHH y promoción de la Ciencia Política, es activista del Centro de Iniciativas democráticas (CIDEM). Global Shaper. Actualmente es asesor jurídico del Departamento de Cooperación Internacional de la Universidad de Panamá.

I Estudiante de IV año de Derecho y Ciencias Políticas de la Universidad de Panamá. Miembro de la Asociación académica de Derecho Internacional (AADI), Universidad de Panamá.

II Estudiante de IV año de Derecho y Ciencias Políticas de la Universidad de Panamá. 
pruebas en dichos procesos ya que hemos podido ser testigos en nuestra vida cotidiana que acciones iniciadas en las redes sociales, tienen efectos fuera del mundo virtual, así como también crear un precedente sobre el tema y dilucidar su nuevo alcance como medio tecnológico de prueba, producto del desarrollo informático que invade nuestras vidas fundamentando así el derecho que pueda generar presentar este tipo de pruebas dentro del proceso.

El presente trabajo fue construido a base de entrevistas realizadas a personas que están en contacto tanto en las redes como en el ejercicio de la abogacía; adicionalmente se utilizó las herramientas de la Internet, noticias, libros informáticos y las fuentes tradicionales de estudio, además de las leyes contenidas en el derecho positivo de nuestra República y la jurisprudencia extranjera.

Por tanto, atendiendo a los criterios anteriormente mencionados y al inminente desarrollo tecnológico de este siglo, así como al impacto que las redes sociales han tenido sobre todo en esta última década, es necesario que las normas y procesos jurídicos evolucionen de la mano con este avance que propone nuevas fórmulas sociales que deben ser utilizadas y adecuadas al sistema jurídico.

Esperamos que este esfuerzo despierte el interés de la comunidad jurídica y con ello una nueva adecuación normativa que nos pueda llevar a pensar en la admisibilidad de la información obtenida en las redes sociales como medio de prueba en el proceso.

III Estudiante de IV año de Derecho y Ciencias Políticas de la Universidad de Panamá. Miembro de la Asociación académica de Derecho Internacional (AADI), Universidad de Panamá.

IV Estudiante de V año de Derecho y Ciencias Políticas de la Universidad de Panamá, actualmente se desempeña como Auxiliar de defensor de oficio en el Instituto de Defensoría de Oficio del Órgano Judicial de la República de Panamá.

v Estudiante de IV año de Derecho y Ciencias Políticas de la universidad de Panamá. Auxiliar de defensor de oficio en el Instituto de Defensoría de Oficio del Órgano Judicial de la República de Panamá.

VI Estudiante de IV año de Derecho y Ciencias Políticas de la Universidad de Panamá.

VII Estudiante de IV año de Derecho y Ciencias Políticas de la Universidad de Panamá. Ganadora del Segundo lugar en el Concurso de Derecho Internacional Dr. Jorge Illueca organizado por el Ministerio de Relaciones Exteriores de la República de Panamá y Naciones Unidas. En Octubre de 2012 fue escogida como estudiante representante de Panamá ante el Foro Internacional de Juventud celebrado en la ciudad de Bakú, Republica de Azerbaiyán.

VIII Estudiante de V año de Derecho y Ciencias Políticas de la Universidad de Panamá.

IX Estudiante de V año de Derecho y Ciencias Políticas de la Universidad de Panamá.

x Estudiante de IV año de Derecho y Ciencias Políticas de la Universidad de Panamá. Pasante, oficial Mayor en el Juzgado de Circuito Civil del Primer Distrito Judicial de la República de Panamá. 
Palabras clave: Redes sociales, documento electrónico, admisibilidad, principio de libertad de medios probatorios, principio de reducción a documento.

\section{Abstract}

The proposed work has as object if to know in what way these proofs are presented, the means of obtaining them and in what way they are admitted and authenticated in a judicial process, besides of understanding the value of these proofs in a process since we have been witnesses in our daily life that actions initiated in the social networks, have effects out of the virtual world, As well as to create a precedent about the subject and to explain a new reach as technological way of proof, product of the IT development that invades our lives basing in this way the right that could generate to show this type of proof inside the process.

The present work was constructed based on interviews realized to persons that are in contact with the social networks as well as working in the legal field; in addition to this, the internet, news, IT books and traditional sources were used as tools, as well as the laws contained in the statute law of our Republic and the foreign jurisprudence.

Therefore, attending to the criteria previously mentioned and to the imminent technological development of this century, as well as to the impact that the social networks have had especially in the latter decade, it is necessary that the procedure and juridical processes evolve of the hand with this advance that proposes new social formulas that they must be used and adapted to the juridical system.

We hope that this effort wakes up the interest of the juridical community and with it a new normative adequacy that it could lead us to think about the admissibility of the information obtained in the social networks as way of proof about the process.

Key words: Social Networks, electronic document, admissibility, principle of freedom of evidence, principle reduction of document. 


\section{CONCEPTOS GENERALES SOBRE LAS REDES SOCIALES COMO MEDIO PROBATORIO}

\subsection{Concepto de Prueba}

El ser humano en su infinita búsqueda por la verdad, necesita la comprobación de todos los fenómenos que le rodean. La prueba se presenta a lo largo de la historia cuando surge la necesidad de probar la verdad de un hecho o acto; y en el campo procesal es fundamental pues está dirigida a producir certeza en el juez sobre la existencia de los hechos.

Existen en la doctrina diversos conceptos de prueba.

Hernando Devis Echandía define la prueba como el "conjunto de reglas que regulan la admisión, producción, asunción y valoración de los diversos medios que pueden emplearse para llevar al juez a la convicción sobre los hechos que interesan al proceso". ${ }^{1}$

$\mathrm{Al}$ respecto, Carnelutti nos define como prueba judicial como "todo medio que sirve para conocer cualquier cosa o hecho, esto es, la totalidad de los medios que pueden servir de conducto al conocimiento por el juez de la cuestión debatida o planteada en cada proceso". ${ }^{2}$

Podemos decir que prueba es toda actuación realizada por las partes en un proceso, que busca lograr el convencimiento del juez acerca de los hechos afirmados; y a la vez, es el conjunto de normas que regulan la admisión, producción y valoración de los medios probatorios.

\subsection{Sistemas sobre medios de prueba}

En la Teoría General de la Prueba Jorge Fábrega menciona los siguientes sistemas sobre los medios de prueba:

1. Taxativamente determinado o Numerus Clausus Prueba Legal; consideraba que expresamente en la Ley constituía una garantía, ya que las personas sabían por anticipado los medios probatorios que se podían utilizar en contra de ellas, esto quiere decir, que la ley estipulaba de modo taxativo e imperativo los medios de prueba que el juez puede admitir y practicar.

2. Sistema Libre o Abierto, Numerus Apertus: La ley señala los medios de prueba sólo a título ilustrativo y deja al juez en libertad para considerar cualquiera otra prueba adecuada.

1 DEVIS ECHANDÍA, Hernando. Teoría General de la Prueba Judicial, Tomo I, Biblioteca Jurídica Diké, Colombia, 1993, p. 15.

2 CARNELUTTI, Francesco. La Prueba Civil, Ediciones Arayú, Buenos Aires, 1955, p. 40. 
Los Códigos modernos, siguiendo las nuevas corrientes doctrinales han dejado atrás el numerus clausus y han adoptado el sistema del numerus apertus. Nuestra legislación, desde la vigencia de la codificación colombiana hasta 1987 señalaba taxativamente los medios de prueba, el nuevo código judicial recoge el nuevo sistema así:

Artículo 780. Sirven como prueba los documentos, la confesión, el juramento, la declaración de parte, la declaración de testigos, la inspección judicial, los dictámenes periciales, los informes, los indicios, los medios científicos y cualquier otro medio racional que sirva a la formación de la convicción del juez, siempre que no estén expresamente prohibidos por la ley ni violen Derechos Humanos ni sean contrarios a la moral o al orden público.

Puede asimismo emplearse calcos, reproducciones y fotografías de objetos, documentos y lugares.

Es permitido, para establecer si un hecho puede o no realizarse de determinado modo, proceder a la reconstrucción del mismo. Si el juez lo considera necesario, puede procederse a su registro en forma fotográfica o electromagnética.

\subsection{Concepto de redes sociales}

Las redes sociales en Internet se han convertido en prominentes herramientas para empresas, artistas, marcas, profesionales independientes y, sobre todo, en lugares para encuentros humanos.

Las profesoras estadounidenses, Danah Boyd y Nicole Ellison, definen las redes sociales como "servicios con sede en la red que permiten a los individuos: a) construir un perfil público o semipúblico dentro de un sistema delimitado o cerrado, b) articular una lista de otros usuarios con los que comparten relaciones, c) ver y recorrer esa lista de relaciones que las personas relacionadas tienen con otras dentro del sistema". ${ }^{3}$

Las redes sociales son estructuras compuestas por un grupo de personas que comparten un interés común, relación o actividad a través de Internet, donde tienen lugar los encuentros sociales y se muestran las preferencias de consumo de información mediante la comunicación en tiempo real, aunque también puede darse la comunicación diferida en el tiempo.

PONCE, Isabel. Redes Sociales, Observatorio Tecnológico [en línea], España: Ministerio de Educación, Gobierno y Deportes, 2012. Recuperado el 10 de mayo de 2013, de: [http://recursostic.educacion.es/observatorio/web/es/internet/web-20/1043-redes-sociales?start=1] 


\subsection{Naturaleza jurídica de las redes sociales como medio probatorio}

La ley no pone una norma que restrinja o prohíba los medios probatorios, más bien, da gabela al numerus apertus, y adecuándolo a la relación hombretecnología y viceversa; consideramos que la información proveniente de las redes sociales es un medio idóneo de prueba.

El principio de predominio del elemento escrito indica que "todos los actos probatorios, deben reducirse a escrito dejándose constancia de ello y, si se incorporan al expediente, la sentencia debe basarse en las diligencias y actas que recogen la instrucción probatoria"; ; el juez prefiere la prueba documental.

La ley 51 de 2008 que regula los documentos electrónicos, las firmas electrónicas y el desarrollo del comercio electrónico; en su artículo 2 en su numeral 17 define como documento electrónico toda representación electrónica que da testimonio de un hecho, una imagen, un sonido o una idea.

Según el profesor Edgardo Villalobos, "los documentos almacenados tecnológicamente constituyen un principio de prueba por escrito y podrán ser complementados por medio de testigos". 5

Partiendo de este principio, y de las definiciones citadas, podemos decir que toda información proveniente de las redes sociales debe considerarse como documento electrónico y debe ser presentada dentro de un proceso por escrito.

\subsection{Características de las redes sociales como medio de prueba}

- Es atípica. Como hemos visto, las pruebas emanadas de las redes sociales no están directamente enunciadas dentro de las normas contenidas en el Código Judicial.

- Es indirecta. Para que las pruebas emanadas de las redes sociales produzcan la convicción del juez, será por medio de un intermediario, una persona o por producto de una cosa; así cuando el perito informático practica la prueba el juez llega a la certeza de los hechos no por él mismo si no por el perito que lo lleva a observar imparcialmente la prueba.

- Es especial. Estas pruebas son especiales porque requiere la aplicación de conocimientos técnicos para su aportación y práctica.

4 FÁBREGA, Jorge. Teoría General de la Prueba, Ediciones Jurídicas Gustavo Ibáñez, Santa Fe de Bogotá, 1997, p. 99.

5 VILLALOBOS, Edgardo. Diccionario de Derecho Informático, Litho Editorial Chen, Panamá, 2002, p. 68. 


\section{El NUEVO ALCANCE DE LAS REDES SOCIALES COMO MEDiO PROBATORIO}

\section{Introducción}

Las redes sociales han tomado mayor relevancia dentro del mundo jurídico. Álbumes de fotos, páginas de perfiles, comentarios en el muro, actualizaciones de estado o "tweets" se han convertido en minas de oro para las pruebas en los juicios.

Actualmente en Estados Unidos, a pesar de que se fomenta mucho la autorregulación, ya se está viendo la posibilidad de hacer una "Social Networking Law" por medio de los académicos.

En Europa, la Comisión Europea está tomando los primeros pasos en cuanto a la regulación de redes sociales. En el 2009 se firmó el primer tratado autorregulatorio de redes sociales, con participantes como Microsoft, Google, Facebook y demás.

Ahora bien, nos hacemos las siguientes interrogantes; ¿Qué alcance puede tener la información proveniente de las redes sociales? ¿Quién tiene la carga de aportar dicha prueba? ¿Qué valor puede tener esta prueba?

La carga de la prueba, "consiste en una regla que le crea a las partes una autorresponsabilidad, para que acrediten los hechos que le sirven de supuesto a las normas jurídicas cuya aplicación reclaman y que, además, le indica al juez cómo debe fallar cuando no aparecen probados tales hechos". ${ }^{6}$

Couture señala que los problemas de la prueba consisten en saber qué es la prueba; qué se prueba; quién prueba; cómo se prueba; qué valor tiene la prueba producida.

Pero la prueba, aparte de ser una carga, se ha convertido en un derecho que incluso tiene protección constitucional.

El derecho a la prueba, como establece Fábrega, "incluye cuatro elementos esenciales, a saber: a) Derecho a obtener las pruebas; b) Derecho a aportar las pruebas; c) Derecho a que se reciba y asuma la prueba; d) Derecho a que se valoren la prueba".

PARRA QUIJANO Jairo, Manual de Derecho Probatorio, Cuarta Edición, Ediciones Librería del Profesional, Colombia, 1994, p. 47.

FÁBREGA, Jorge. Teoría General de la Prueba, Op. cit. p. 43. 


\subsection{Relación entre el derecho a la prueba y la carga de la prueba con las redes sociales}

Para la mejor comprensión del presente trabajo es necesario establecer una relación entre estos dos elementos, el derecho a la prueba y la carga de la prueba, al respecto podemos mencionar lo siguiente:

El derecho a la prueba, según M.S. Midón es aquel que posee el litigante, consistente en el poder de utilización de los medios probatorios necesarios para formar la convicción del órgano jurisdiccional acerca de lo discutido en el proceso $^{8,}$ mientras que la carga de la prueba se refiere a una regla procesal que "le crea a las partes una autorresponsabilidad, para que acrediten los hechos que le sirven de supuesto a las normas jurídicas cuya aplicación reclaman y que, además, le indica el juez cómo debe fallar cuando no aparecen probados tales hechos"

Esto nos lleva a establecer cómo se dan estos dos elementos de la prueba dentro de las redes sociales, y es que en las redes sociales se dan todo tipo de actos, producto de la convivencia humana, lo cual en algunas situaciones llega a hacer que los intereses de una persona, o de una colectividad de personas se vean afectados a causa de los hechos dados en el mundo virtual, lo cuales constituyen medios de pruebas y de acuerdo a nuestro entendimiento, el litigante tiene la facultad de presentar una prueba que se de en uno de estos espacios, y de acuerdo a la carga de la prueba que representa una regla de autorregulación para acreditar los hechos probados, el litigante está en la obligación de acreditar estos hechos alegados, por lo tanto, si existe la prueba obtenida por una red social, la misma debe ser aportada y admitida en un proceso.

\subsection{Alcance de la información obtenida de una red social}

A continuación explicaremos qué alcance puede tener la información contenida en una red social, y su relevancia en determinadas áreas del Derecho.

En el derecho laboral las redes sociales, sobre todo Facebook, han sido empleadas en múltiples ocasiones por las empresas como medio de prueba para un despido según la jurisprudencia extranjera. Así ha sucedido en los últimos años con trabajadores que estando de baja han publicado en Facebook fotos de fiestas, otros que han injuriado a sus compañeros o jefes en las redes, o aquellos que han colgado imágenes de la oficina en las que aparecen en actitudes poco

MIDON, Marcelo Sebastián. Derecho Probatorio, Ediciones Jurídicas Cuyo, 2007, p. 36.

PARRA QUIJANO, Jairo. Manual de Derecho Probatorio, Ediciones Librería del Profesional, 1996, p. 47 
decorosas o no aptas de acuerdo a su labor. En estos casos, dado que en materia laboral predomina el principio de libertad de la prueba que consiste en que las partes pueden aportar las pruebas de los hechos por cualquier medio, así como también el principio de disponibilidad de las pruebas, que indica que si la parte contraria a la que, según las reglas generales, tiene en su poder la prueba necesaria acreditar los hechos fundamentados en la pretensión, tiene entonces la carga de probar, para estos efectos, el empleador.

Nuestra legislación nacional no permite la utilización de redes sociales para que un empleador despida a su empleado, pero si la consideramos válida para demostrar que se incumplió con alguna de las cláusulas del contrato laboral lo cual es causal de despido.

Sin embargo, en la rama penal la utilización de redes sociales ha causado un gran impacto por el uso que se les ha dado a las mismas, incluso para difamar u hostigar incurriendo así en delitos contra el honor, como sucede con el llamado cyberbullying que no es más que el uso de estas redes sociales para acosar cibernéticamente a una persona o un grupo de personas. Tanto el cyberbullying como otras conductas adoptadas en las redes sociales han sido objeto de querellas.

Como evidencia en materia penal, ha sido objeto de numerosas controversias que aluden a que los distintos jueces en su sana crítica, admitan o no este tipo de pruebas. Aun así, la jurisprudencia indica que en más de una ocasión publicaciones en Facebook, videos en YouTube o comentarios en Twitter han sido material útil y relevante como elemento de prueba, y que lo más apto sería crear un sistema que respaldara legalmente la forma de obtención y aporte de lo publicado en las redes sociales al proceso penal para que tanto los funcionarios y auxiliares de la justicia como las partes; puedan emplear, bajo un criterio ya preestablecido; provechosamente este creciente recurso probatorio en los tribunales con el fin de complementar las corrientes tecnológicas con el marco penal.

Por otro lado, en el derecho comercial ha sido uno de los más evolutivos en materia tecnológica debido a que su propia naturaleza global le impulsa a ir de la mano con los avances de la tecnología. Transacciones, firmas electrónicas ya han sido medios de prueba admitidos por los tribunales, y bien podrían las redes sociales fungir como "documentos" útiles para los litigantes.

Actualmente estas mismas redes sociales, sobre todo Facebook y Twitter, son empleadas como medios publicitarios, ya que representan una forma rápida y eficaz de llegar a los consumidores. El contraste está en que estas publicidades podrían ser engañosas o que por otra parte, puedan violentar los derechos al 
consumidor y con esto desencadenar el conjunto de problemas jurídicos que ello comporta.

En el ámbito del Derecho Civil, las redes sociales son potencialmente útiles para el perfeccionamiento de contratos consensuales, ya que estas plataformas digitales son utilizadas por distintas personas para entablar relaciones que pueden generar posibles obligaciones, y esta información contenida en las redes sociales pueden servir como medio para probar cualquier obligación establecida dentro de las mismas. Corresponderá dentro de un proceso aportar dicha prueba a quien alegue un hecho.

\section{AdMISIBILIDAD Y AUTENTICACIÓN DE LAS REDES SOCIALES COMO MEDIO PROBATORIO}

Antes se utilizaba la tecnología como fundamento práctico, pero ya hemos superado esta fase y es necesario que las relaciones que se entablan a través de las redes sociales tengan valor jurídico equivalente a las realizadas de formas tradicionales.

Es preciso que se le dé reconocimiento de valor y eficacia jurídica a las pruebas obtenidas de las redes sociales teniendo en cuenta los siguientes puntos:

- Determinar la autoría de los perfiles de las redes sociales.

- Garantizar la confidencialidad.

- Certificar la información dentro de la red social.

- Verificar el intercambio de información.

- Garantizar que no existan alteraciones.

Todo esto debe hacerse en un marco virtual a través de instrumentos que precisan el reconocimiento legal de su eficacia jurídica.

Establezcamos como marco de referencia la implementación de la firma electrónica, la cual consiste en relacionar de forma directa un documento que es firmado, dándole validez y seguridad. Las redes sociales carecen de un mecanismo que garantice y determine la autoría de la información cargada, que acredite el supuesto perfil. Somos de la convicción que en el futuro, existirá dicho sistema para las redes sociales.

\subsection{Admisibilidad}

Al referirnos sobre la admisibilidad de los medios probatorios podemos decir que son admisibles como prueba todos aquellos elementos que 
puedan producir convicción en el ánimo del juzgador acerca de los hechos controvertidos o dudosos.

Para determinar la admisibilidad de la información proveniente de las redes sociales como prueba, debemos tomar en cuenta la clasificación de la misma como documento electrónico.

La ley 51 de 2008 establece en su artículo 7 la admisibilidad y fuerza probatoria de los documentos electrónicos:

Artículo 7. Admisibilidad y fuerza probatoria de Documentos Electrónicos. Los documentos electrónicos serán admisibles como medios de prueba y tendrán la misma fuerza probatoria otorgada a los documentos en el Libro Segundo de Procedimiento Civil del Código Judicial.

En todo caso, al valorar la fuerza probatoria de un documento electrónico se tendrá presente la confiabilidad de la forma en la que se haya generado, archivado o comunicado, y la confiabilidad de las formas en la que se haya conservado la integridad de la información.

Al analizar el artículo anterior podemos decir que una prueba obtenida a través de una red social es totalmente admisible, y el juzgador no debe encontrar obstáculo alguno al recibir dicha prueba.

Ahora bien, nos surgen las siguientes interrogantes; $¿$ Es una prueba de una red social lícita? ¿Vulnera la intimidad de las personas?

Generalmente la prueba ilícita se relaciona con la ilicitud o ilegitimidad de los medios utilizados para obtenerla o aportarla al proceso: fuerza o violencia, tortura o en violación al conjunto de normas que tutelan el derecho a la intimidad, este último recogido en el artículo 29 de la Constitución, el cual puede ser objeto de confusión con el tema que nos ocupa.

Dentro de las condiciones que las redes sociales establecen para ser parte de ellas, por ejemplo, Facebook, maneja la información que una persona desea compartir de la siguiente manera: "compartimos tu información con terceros cuando creemos que dicha acción está permitida por ti, que es razonablemente necesaria para ofrecer nuestros servicios o cuando se nos exige legalmente que lo hagamos". Más adelante reconoce los riesgos inherentes al compartir información "aunque te permitimos definir opciones de privacidad que limiten el acceso a tu información, ten en cuenta que ninguna medida de seguridad es perfecta ni impenetrable"; y más allá no se hacen responsables de cualquier vulneración de esta privacidad, "no podemos controlar las acciones de otros usuarios con los que compartas información. No podemos garantizar que sólo vean tu información personas autorizadas. No podemos garantizar que la información 
que compartas en Facebook no pase a estar disponible públicamente. No somos responsables de que ningún tercero burle cualquier configuración de privacidad o medidas de seguridad en Facebook". ${ }^{10}$

Como podemos ver, al referirnos sobre la información cargada, compartida o suministrada a través de las redes sociales, no podemos hablar de una privacidad como tal, ya que no existe. La mal llamada "privacidad" dentro de las mismas no es segura y eficaz, e inclusive, nos atrevemos a decir que el uso de una red social no es privado, sino algo completamente público.

Tomando en cuenta estas consideraciones, llegamos a la siguiente conclusión: una prueba sustraída de una red social es completamente lícita, y puede ser admitida dentro de un proceso legal sin ningún obstáculo.

\subsection{Autenticación}

Nos referimos a autenticación al mecanismo mediante el cual se sientan las bases para que una prueba u objeto sea admisible dentro de un proceso. La autenticación tiene mucho que ver con la acreditación porque a través de esta es que se realiza la misma, la cual busca convencer al juez.

$\mathrm{Al}$ hablar de la información proveniente de redes sociales como medio de prueba, debemos considerar lo siguiente para su autenticación: el aseguramiento de pruebas y la diligencia virtual.

\subsection{Aseguramiento de Pruebas}

Las pruebas provenientes de redes sociales, debido a su especial carácter tecnológico y su fácil manipulación, estimamos que el aseguramiento de pruebas es fundamental para la autenticación de las mismas y su posterior admisibilidad dentro de un proceso.

Respecto al aseguramiento de pruebas podemos decir que "el mismo tiene como finalidad garantizar la existencia de los objetos o estados de cosas, con valor probatorio, que estuvieren amenazados de alteración o desaparición, de tal modo que al momento de practicar la prueba pudiera no existir o hacerlo de forma distinta". ${ }^{11}$

10 FACEBOOK. Política de Privacidad de Facebook, Facebook Site Governance Notas [en línea], España, 2009. Recuperado el 11 de mayo de 2013, de: https://www.facebook.com/note.php?note_id $=+322317115300$

11 GIL VALLEJO, Beatriz. El Aseguramiento de la prueba en el proceso civil y penal, Bosch Editor, España, 2011, p. 35. 
En el artículo 815 de nuestro Código Judicial se establece el aseguramiento de pruebas:

Artículo 815. Cuando una persona pretenda demandar o tema que se le demande y existe temor justificado de que eventualmente pueda faltarle un medio de prueba o hacérsele difícil o impracticable su obtención en el momento oportuno, puede solicitar al juez que se practique de inmediato cualquiera de las siguientes pruebas...

Más adelante en el artículo citado en su numeral dos enuncia la inspección judicial y los dictámenes periciales, los cuales a nuestro criterio, son los métodos aplicables al objeto de nuestro estudio.

\subsubsection{Inspección judicial}

La inspección judicial, antes llamada inspección ocular, consiste en el examen y reconocimiento que hace el juez de determinadas cosas relativas al proceso.

Devis Echandía define la inspección judicial como la "diligencia procesal practicada por un funcionario judicial con el objeto de obtener argumentos de prueba para la formación de su convicción, mediante el examen y observación con sus propios sentidos de hechos ocurridos durante la diligencia o antes, pero que subsisten o dé rastros o huellas de hechos pasados y en ocasiones de su reconstrucción". 12

Ahora bien, pasemos a la inspección judicial como aseguramiento de pruebas.

La inspección judicial como aseguramiento de pruebas es contemplada en el artículo 828 del Código Judicial. El mismo dispone que tal medida puede solicitarse para la inspección de lugares y cosas que hayan de ser materia del proceso cuando en el transcurso del tiempo haga difícil su esclarecimiento o cuando su conservación en el estado en que se encuentra resultare difícil o improbable.

La inspección judicial puede efectuarse con la concurrencia de peritos y podría anexarse la exhibición de cosas muebles.

La diligencia puede ser solicitada por los presuntos demandantes y demandados, debe solicitarse al juez competente para conocer de la demanda, debe otorgarse caución de daños y perjuicios; puede verificarse con o sin la concurrencia de la contraparte, teniendo que ratificarse tal prueba en el proceso cuando no haya concurrido la parte contraria.

12 DEVIS ECHANDÍA, Hernando. Teoría General de la Prueba Judicial. Op. cit. p. 234 
Consideramos que el artículo al referirse de la inspección de cosas, las redes sociales entran en esta categoría; las mismas pueden perecer y perder su valor jurídico. Dicha inspección debe realizarse a través de un ordenador con acceso a Internet, y estimamos fundamental la presencia de un perito especialista en informática.

\subsubsection{Dictámenes periciales}

Cuando, en sentido general, dentro del proceso se requieran conocimientos especializados, se debe acudir a aquellas personas con estudios y experiencia técnica, científica o artística.

El autor Jairo Parra Quijano nos define el dictamen pericial como "un medio de prueba que consiste en la aportación de ciertos elementos técnicos, científicos o artísticos que, la persona versada en la materia de que se trate, hace dilucidar la controversia, aporte que requiere especiales conocimientos". ${ }^{13}$

Así como un testimonio o un documento, el dictamen pericial lleva al juzgador nuevos conocimientos que pudieran esclarecer un proceso.

Específicamente para la información proveniente de las redes sociales, es necesarios peritos informáticos. El perito informático debe poseer un perfil específicamente técnico, siendo de vital importancia que esté familiarizado con las técnicas de análisis y recuperación de datos. El perito deberá recopilar la información que es puesta a su disposición, analizar la misma en busca de los datos requeridos y emitir un informe o dictamen en donde vuelque las conclusiones de la investigación realizada.

Dentro del informe pericial, es importante resaltar que el perito puede concluir si ha detectado alguna manipulación de la información o si todos los datos son verdaderos y por lo tanto no hay indicios de manipulación.

\subsection{Diligencia Virtual}

El notario es un Ministro de Fe que garantiza la legalidad de los documentos que interviene, y cuyos actos se hallan investidos de la presunción de verdad, propia de los funcionarios públicos, estando habilitado por las leyes y reglamentos para conferir fe pública de los contratos y actos extrajudiciales.

Para poder autenticar la información proveniente de las redes sociales, el notario realiza una diligencia virtual, la cual consiste en una atestación notarial de lo que el notario observa desde un ordenador dentro de la red social y da fe

13 PARRA QUIJANO Jairo, Manual de Derecho Probatorio, Op. cit. p. 351. 
de lo que percibe. Este procedimiento debe realizarse con la persona dueña de la cuenta de la red social.

El notario realiza un acta de mera percepción, el cual contiene el día, hora, descripción del ordenador, y la información descrita de la red social; sin emitir juicio u opinión alguna al respecto de lo que observa. Luego anexa la impresión de la página web y, sella y firma el acta.

\subsection{Pruebas emanadas de las redes sociales}

\subsubsection{Redes Sociales}

Dentro de este punto vamos a desarrollar los tipos de pruebas que pueden sustraerse de las redes sociales.

\subsubsection{YouTube}

YouTube es un sitio web de vídeos fundado en febrero de 2005 que permite que millones de usuarios encuentren, vean y compartan vídeos originales. YouTube ofrece un foro para comunicarse con los usuarios de todo el mundo, para informarles y para inspirarlos y sirve como plataforma de difusión para creadores de contenido original y anunciantes de cualquier tamaño.

Dentro de esta red social, podemos sustraer videos como medios probatorios. Los mismos serán tratados como documento escrito según el artículo 832 del Código Judicial.

\subsubsection{Facebook}

Originalmente era un sitio para estudiantes de la Universidad de Harvard, pero actualmente está abierto a cualquier persona que tenga una cuenta de correo electrónico. Los usuarios pueden participar en una o más redes sociales, en relación con su situación académica, su lugar de trabajo o región geográfica.

Servicios que ofrece mediante los cuales se puede obtener una prueba:

Lista de amigos: En ella, el usuario puede agregar a cualquier persona que conozca y esté registrada, siempre que acepte su invitación.

De esta manera podemos ver cuáles son las conexiones de la persona a investigar, en qué círculo social la misma se maneja, a modo de ejemplo podemos señalar que los bancos que utilizan la política "conoce a tu cliente" se basan en la información obtenida de esta antes de otorgar un préstamo o realizar transacciones con la persona. 
Chat: Servicio de mensajería instantánea en dispositivos móviles y computadores a través de Facebook Messenger.

Estas conversaciones son útiles para la rama del derecho, ya que la información compartida permanece guardada en los servidores del mismo, y los dueños de estas conversaciones pueden acceder a la misma mediante una computadora o su dispositivo móvil.

En el muro de cada usuario se comparten desde pensamientos, música, imágenes y demás información que podrá ser utilizada en un proceso para determinar el perfil de la persona, esto puede ser útil en la rama penal para determinar el perfil del encuestado.

Estas pruebas que regularmente se presentan en un proceso, en diferentes ramas del Derecho denotan como las personas llegan al tribunal presentando fotos de algún hecho, indistintamente si la misma - la foto - es válida o no, y dependiendo del proceso, la misma será admitida o no.

\subsection{Twitter}

Twitter es una red de información en tiempo real que conecta a sus usuarios con las últimas historias, ideas, opiniones. Localiza las cuentas que resulten más atractivas al usuario y siguiendo sus comentarios en tiempo real y funciona a través de pequeñas explosiones de información llamadas tweets.

Al igual que Facebook, podemos sustraer fotos, videos, mensajes directos entre usuarios, y lo más importantes, los tweets.

Resaltamos la importancia de los tweets ya que pueden convertirse en hechos notorios con consecuencias jurídicas relevantes, como lo son los publicados por los Jefes de Estado, con una trascendencia que inclusive son publicados en otros medios de comunicación. ${ }^{14}$

\subsection{Valoración de las pruebas provenientes de redes sociales}

Las pruebas provenientes de la información de redes sociales serán valoradas por las reglas de la sana crítica.

La Sana crítica:

Concepto: Para Guillermo Cabanellas de Torres, en su diccionario jurídico la misma es:

14 Al respecto podemos decir que existe una denuncia presentada en la Asamblea Nacional contra el Presidente de la República sobre el tweet que publicó sobre el caso FEPAFUTCervecería del Barú. 
"Fórmula leal para entregar al ponderado arbitrio judicial la apreciación de las pruebas, ante los peligros de la prueba tasada y por imposibilidad de resolver en los textos legales la complejidad de las situaciones infinitas de las probanzas."

Podemos ver entonces que la misma es la acción mental que realiza el juez al momento de evaluar la prueba teniendo en cuenta los siguientes elementos:

- La Experiencia

- Máxima de la conducta humana

- La lógica

- La Razón

- La doctrina

Nuestra legislación regula lo referente a la sana crítica en el Código Judicial en su artículo 781 de la siguiente manera:

Artículo 781. Las pruebas se apreciarán por el juez según las reglas de la sana crítica, sin que esto excluya la solemnidad documental que la ley establezca para la existencia o validez de criterios, autos o contratos.

El Juez expondrá razonadamente el examen de los elementos probatorios y el mérito que le corresponde.

\section{LA PRUEBA OBTENIDA DE UNA RED SOCIAL VS EL DERECHO A}

\section{LA INTIMIDAD}

\subsection{Derecho a la intimidad}

La intimidad es, el derecho a no ser conocidos, en ciertos aspectos, por los demás. Es un derecho al secreto, a que los demás no sepan lo que somos o lo que hacemos.

En cuanto al derecho a la intimidad, la Constitución Política de Colombia dispone lo siguiente:

Artículo 15. Todas las personas tienen derecho a su intimidad personal y familiar y a su buen nombre, y el Estado debe respetarlos y hacerlos respetar. De igual modo, tienen derecho a conocer, actualizar y rectificar las informaciones que se hayan recogido sobre ellas en bancos de datos y en archivos de entidades públicas y privadas.

Por su parte la Constitución Española indica que:

Artículo 18, numeral 1. Se garantiza el derecho al honor, a la intimidad personal y familiar y a la propia imagen. 
De igual forma somos conscientes de que el objeto del derecho a la intimidad no es únicamente impedir intromisiones ilegítimas en la esfera privada, sino también evitar que los datos obtenidos sean utilizados o transferidos sin el resguardo y control que pueda tener la persona; de este modo se elimina -al menos parcialmente- el llamado "rumor informático".

No obstante, en el caso de las redes sociales, no existe una real vulneración del derecho a la intimidad, sino que el individuo tutelar del derecho cede la información libre y públicamente, lo que implica que dada la repercusión que tiene la información actualmente, la cual se ha constituido en la principal herramienta para el aprovechamiento de la producción e intercambio de bienes y servicios, así como en un eje básico para la solución de conflictos legales; sea utilizada.

El derecho a la intimidad consiste por tanto, como derecho constitucional reconocido y tutelado en aquella esfera o ámbito estrictamente personal e íntimo de la persona humana, el cual debe estar excluido del conocimiento de terceras personas, a fin de evitar o impedir intervenciones innecesarias en dicha esfera de la privacidad con miras a preservar su dignidad como individuo.

Hoy en día existen múltiples dudas sobre la utilización de las redes sociales como medios tecnológicos de prueba que aluden a si surge o no una violación a la intimidad del individuo, puesto que todas las personas tienen aquella parte de su vida que no está dedicada a una actividad pública y que por lo tanto debe estar libre del acceso de terceros.

Es al individuo a quien le compete revelar o no datos sobre su vida personal, solo es él quien debe decidir con completa libertad, cuando y cuanto de dicha información quiere revelar y a quien o quienes revelarlo o bien mantenerlo en secreto y es precisamente esto lo que sucede a través del uso de las redes sociales como Facebook o twitter en donde la persona decide que contenido sobre su vida privada desea o no publicar.

Resulta extraordinario observar cómo estamos ya no solo frente a un derecho a la intimidad que juega su papel individualmente, sino que ante la utilización de las innovaciones existentes se convierte en un derecho que en sí mismo es considerado como un derecho fundamental, pero que se enlaza de esta manera con la denominada libertad informativa o autodeterminación informativa que tiene la persona.

Es así como se llega a un concepto más amplio de intimidad y se habla del derecho a la intimidad como un derecho de la personalidad, irrenunciable, en el que la persona reiteramos es la única legitimada para autorizar la divulgación de sus datos personales. 
La libertad informática ha sido estudiada en la doctrina por diversos autores como Carlos Barriuso Ruiz quien señala que la misma consiste en un derecho de control efectivo, por uno mismo, de la información que le concierne y de la salvaguardia de su intimidad y Frossini por su parte lo define como el derecho a disponer de la información, de preservar la propia identidad informática o lo que es lo mismo la persona tiene el derecho de consentir, controlar y rectificar los datos informativos concernientes a su personalidad.

De esta manera observamos como el marco del derecho a la intimidad respecto a la utilización de las redes sociales se expande y la libertad informática llega a jugar un papel importante al representar una evolución y garantía de la intimidad en nuestros días, al darle al individuo, titular de la información, un poder de control de los datos que le conciernen; puesto que el tradicional aspecto negativo de la intimidad en torno a la utilización de las redes sociales para ser utilizadas como medios de prueba hoy se ve envuelto en una polémica constante sobre como implica o no el respeto al derecho de la intimidad de la persona y su posible vulneración.

Cada vez más las nuevas tecnologías forman parte de nuestro mundo cotidiano y estamos expuestos con o sin nuestro consentimiento, a una gran cantidad de datos personales que pueden llegar a ser utilizados con fines diversos a los autorizados aunado a la gran facilidad que existe también de acceder a los datos personales de una persona a través de programas de "data mining"15 dedicados a buscar información sensible escondida dentro de bases de datos que pueden llegar a mostrar una silueta virtual perfecta de la vida de un individuo.

En una sociedad que marcha al progreso de la tecnología, el tratamiento de datos hace mayormente identificable al sujeto, en virtud de que la recolección de datos hace posible las contrataciones electrónicas, el intercambio comercial y las comunicaciones.

Si bien el impacto de las tecnologías en nuestra sociedad, aseguran muchos trae como resultado una interacción cada vez más estrecha entre estas y los individuos , aumentando así las posibilidades de que, a través de esa interacción , se vulneren los derechos fundamentales y es que la tradicional concepción del derecho a la intimidad en cuanto a la utilización de redes sociales no alcanza a proteger del todo a la persona ante los nuevos escenarios por lo cual se ha hecho necesario entender la intimidad mancomunadamente al derecho a la libertad informática y el derecho a la protección de datos persona.

15 La minería de datos, es un campo de las ciencias de la computación referido al proceso que intenta descubrir patrones en grandes volúmenes de conjuntos de datos. El objetivo general del proceso de minería de datos consiste en extraer información de un conjunto de datos y transformarla en una estructura comprensible para su uso posterior. 


\section{JURISPRUDENCIA EXTRANJERA ACERCA DE LAS REDES SOCIALES COMO MEDIO DE PRUEBA}

La información proveniente de las redes sociales en los tribunales de justicia es parte del fenómeno de la globalización, debido a esto, no es sorpresivo que en otros países se hayan utilizado pruebas obtenidas de las redes sociales para intentar probar situaciones que se manifiestan en el mundo real, es decir, situaciones provocadas en el mundo virtual de las redes sociales que tienen efectos en la realidad.

Por tanto, es necesario hacer un estudio a nivel internacional de estas situaciones y ver qué soluciones han dado los magistrados de otros países para solventar este nuevo tipo de pruebas ya que, debido a la evolución tecnológica del mundo, es algo innovador para la ciencia del Derecho y sus diversas ramas.

\subsection{En materia laboral}

Encontraremos casos en que justifican despidos por información proveniente de las redes sociales, en donde es notorio que el trabajador ha incumplido con las disposiciones contractuales de su contraparte -el empleador- y la misma utiliza la información proveniente de estas redes sociales, como lo es Facebook y el Tribunal se pronuncia en base a esta información.

Como el Tribunal Superior de Madrid que acepta las fotos obtenidas de Facebook como medio de prueba para justificar despidos.

\section{Sentencia del Tribunal Superior de Madrid de 23 de enero de 2012.}

Se declara la procedencia de un despido por quebranto de la buena fe de un trabajador en situación de baja temporal por depresión, tras constatar el empleador por unas fotos publicadas en Facebook, que el trabajador realizaba salidas nocturnas y consumía alcohol.

La publicación de fotos o videos que denoten un perjuicio al empleador pueden ya ser empleadas como prueba para justificar un despido por incumplir un contrato en el cual se estipulan que conductas están o no prohibidas al trabajador, teniendo en cuenta que en un principio el trabajador está aceptando al momento de firmar el contrato prohibiciones o limites que debe respetar en cuanto al desarrollo de su actividad laboral, estando consciente de que incurre en grave error en su actuar al momento de hacer tales publicaciones.

Consideramos que en esta ocasión el despido si es justificado en primer lugar porque como bien se menciona en el Estatuto de los Trabajadores, norma que regula las relaciones de trabajo en España; en su artículo 54, la transgresión 
de la buena fe, así como la falsa justificación de su baja temporal son causales de despido disciplinario.

A través de esta sentencia evidenciamos como la nueva era de las tecnologías ya son utilizadas en otras legislaciones en materia laboral en que se permite empleo de las Social networks (redes sociales) como herramienta de utilidad al momento de probar un hecho, un paso hacia adelante que se refleja al ver que estudiosos del Derecho y Jueces ya se abren a la posibilidad del empleo de las mismas y admitiendo su uso.

\subsection{En Materia Penal}

Las redes sociales, por considerarse como un medio de comunicación e intercambio de información debido a las facilidades que esta implica para conectar con diferentes personas, son también utilizadas para cometer delitos, ${ }^{16} \mathrm{y}$ hoy en día la tendencia señala que es uno de los medios preferidos por las personas para cometer delitos debido a la escasa regulación que las redes sociales implican.

\section{Audiencia Nacional, Sala de lo Penal, Sección 1 ${ }^{a}$, Sentencia de 17 Ene. 2012, $\mathrm{N}^{\circ}$ de Sentencia 2/2012 | $\mathrm{N}^{\circ}$ de Recurso: 8/2011.}

Comentarios en la red social Tuenti en los que se elogian los asesinatos de dos miembros de la Guardia Civil y se reclama la misma "suerte" para otros miembros de los cuerpos de seguridad.

En este caso el Tribunal argentino se encargó de dar conceptos y establecer las diferencias entre difusión y público en general, señalando que la información publicada en Tuenti debe ser considerada como difusión debido al carácter casi privado que tiene la red social en cuestión.

Concepto de difusión, no equiparable a "público en general".

Se estima que pudieron ser vistos, dado el carácter "cuasi público" del perfil del que era titular el acusado, por decenas de miles de usuarios. El hecho de que se trate de una red social a la que solo pueden acceder usuarios determinados no resulta incompatible con el concepto de difusión, pues estos usuarios pueden ser millares. Irrelevancia del número de personas que accedan a un determinado contenido, siendo lo importante que las fotos y los comentarios se publicaron para su lectura por otros, que pudieron acceder a la información.

16 NOTUS. "Mata a su 'mejor amiga' de 65 puñaladas por subir fotos al Facebook". México, 2014. Recuperado de [http://notus.com.mx/mata-su-mejor-amiga-de-65-punaladas-porsubir-fotos-al-facebook/]. 
También se pronunció en cuanto a la libertad de expresión y secreto de las comunicaciones, señalando lo referente a la legalidad de la prueba incriminatoria y reconoció la posibilidad de que la empresa Tuenti suministre información en procesos judiciales mediante autorización judicial para acceder a la identificación del usuario mediante su dirección IP.

\section{Conclusión}

Hemos visto que las herramientas digitales son un camino innovador para todos los profesionales del mundo, y han impactado profundamente nuestra forma de vivir en sociedad.

El Twitter ya lo tenemos aquí, el Facebook al igual que ayer el fax ya lo tenemos; estos múltiples procesos de desarrollo informativo, entre otros, nos plantean la necesidad de revisar nuestro modelo vigente de las leyes actuales en Panamá.

¿Por qué no adoptamos medios modernos de prueba?

La prueba digital le plantea al juez que le evaluará un nuevo reto de confiabilidad unido a todo el mito de la complejidad del mundo electrónico.

Es forzoso concluir que nuestra norma vigente ha tenido un gran avance en materia probatoria, sin embargo requiere de perfeccionamiento.

Nuestro ordenamiento jurídico carece de una legislación y jurisprudencia que arroje luz en el ámbito de la admisibilidad de la evidencia electrónica, específicamente la evidencia obtenida a través de perfiles de redes sociales.

Por otro lado se deben aprobar leyes que provean protección a los usuarios que utilicen el ciberespacio y no que dichos usuarios estén protegidos solamente por los términos y condiciones de las páginas de internet, llámese Facebook, Twitter o plataformas como YouTube.

\section{RECOMENDACIONES}

Luego de nuestro análisis llegamos a establecer nuestra nueva teoría legal o propuesta de adecuación para incluir a las redes sociales en nuestra legislación vigente como medio de prueba, considerando lo siguiente:

1. Las reglas del derecho común y de otros sistemas jurídicos pueden constituir material útil para el estudio del tema que planteamos. Debemos observar el derecho comparado, investigar y tomar de referencia el modelo de otros países que han comenzado a realizar cambios sustanciales en sus legislaciones al respecto. 
2. Elaborar una legislación con la participación multidisciplinaria que refleje la realidad heterogénea de la sociedad. Como vimos, las redes sociales pueden tener alcance dentro de varias ramas del derecho, por lo tanto estimamos necesaria una legislación que involucre estas disciplinas.

3. Se necesita la separación de conceptos: regulación de Internet y regulación de redes sociales. No se pueden legislar las relaciones interpersonales que tienen los usuarios en las redes sociales, pero sí las actividades comerciales, la publicidad y las operaciones que hacen en las redes. Se debe crear una ley que abarque la protección de datos personales, confidencialidad de los usuarios que participan en redes sociales, y la confiabilidad al realizar transacciones electrónicas. Debe existir una identificación electrónica para asegurar la identidad de las personas al ingresar a una red social.

4. Las redes sociales deben ser monitoreadas para evitar abusos de uso de identidad y violación a la privacidad. El usuario debe tener el derecho de revocación, en donde deberán ser eliminados sus datos personales para siempre.

5. Consideramos que exigir una nueva legislación concierne a todos, porque representa en nuestra realidad social una necesidad indispensable que no es un asunto exclusivo de la judicatura o legislatura. Plantear nuestras inquietudes, posibles críticas o aportes sobre el tema de la utilización de las redes sociales como medio de prueba, y que nuestros planteamientos puedan servir como punto de partida e inspiración para marcar el inicio hacia los nuevos cambios que se requieren como futuros profesionales. La comunidad legal debe mantenerse alerta a la nueva realidad social y observar el incremento en el uso de las redes sociales como medios de comunicación de preferencia en la población, y que éstas pueden llegar a generar evidencia a través de los medios de comunicación electrónica. En ocasiones la información proveniente de una red social se convierte en la única prueba disponible para probar un hecho durante un proceso.

6. Los requisitos de autenticación no pueden trabajar en un vacío o abstracto, y aunque deben tener la visión de una tecnología en crecimiento, los estándares deberán ser seguros, viables, y que permitan obtener alternativas claras para la autenticación de la evidencia de una manera tan certera como lo estima la prueba.

7. Es el momento de un nuevo avance, se debe disponer de ejemplos de autenticación o identificación para la información en el perfil de redes sociales, aun cuando en nuestra norma no cuenta con una limitación porque nos regimos por el sistema numerus apertus. 
8. En cuanto a la autenticación de la información debemos dejar de manera muy clara que cada perfil de una red social como Facebook tiene su propia dirección global de documentos y de otros recursos en la red " $w w w$.", o localizador de recurso uniforme. Esta información puede identificar de qué perfil proviene la comunicación y quién es el autor de ese perfil, característica distintiva que podría utilizarse para establecer una nueva forma particular de autenticar un perfil de redes sociales, y dar certeza de la procedencia de la información.

9. Referente al valor probatorio de mensajes de datos, debe existir una validación de identidad, mediante una firma electrónica al dar de alta una cuenta en la red social; se deberá contar con certificados de autenticidad, administrar los registros de la IP con la finalidad de ligar las actividades dentro de una red social con su autor.

\section{REFERENCIAS}

CARNELUTTI, Franceso. La Prueba Civil, Ediciones Arayú, Buenos Aires, 1955.

CHULIÁ, Francisco Vicent. Compendio Crítico de Derecho Mercantil, Bosch Editor, Segunda Edición, España, 1986.

DEVIS ECHANDÍA, Hernando. Teoría General de la Prueba Judicial, Tomo I, Biblioteca Jurídica Diké, Colombia, 1993.

FÁBREGA, Jorge. Teoría General de la Prueba, Ediciones Jurídicas Gustavo Ibáñez, Santa Fe de Bogotá, 1997.

GIL VALLEJO, Beatriz. El Aseguramiento de la prueba en el proceso civil y penal, Bosch Editor, España, 2011.

PARRA QUIJANO Jairo, Manual de Derecho Probatorio, Cuarta Edición, Ediciones Librería del Profesional, Colombia, 1994.

VILLALOBOS, Edgardo. Diccionario de Derecho Informático, Litho Editorial Chen, Panamá, 2002.

CONCEPCIÓN ARAÚZ, Maribel del Carmen. Apreciación de la prueba pericial en el proceso penal, Tesis, Universidad de Panamá, Panamá, 2006.

VILLALÁZ JULIO, Doris Itzel. La diligencia exhibitoria y la inspección judicial en el proceso civil y el comercial, Tesis, Universidad de Panamá, Panamá, 1999.

DURANTE RINCÓN, Esther. Trascendencia del uso de las redes sociales y el BlackBerry Messenger en la mundialización de disturbios civiles en Oriente Medio, Europa y Norteamérica. Quorum Académico, Vol. 9, No.1, 2012. 


\section{Revistas}

GONZÁLEZ RIVERA, Catherine Dimargie. "Facebook, Twitter, YouTube y My Space: Autenticación y admisibilidad de la evidencia electrónica obtenida de perfiles de redes sociales, correos electrónicos y SMS mensaje de texto, un nuevo alcance del descubrimiento de prueba (cambio sustancial en las nuevas reglas de evidencia y procedimiento civil)", En: Revista de Derecho Puertorriqueño, Vol. 51, Puerto Rico, 2011.

MORENO, Víctor. "Documento electrónico y su incidencia en el manejo de la información privilegiada o que involucre derechos privados de las personas", En: Revista de Reconocimiento a la Facultad de Derecho en sus 90 años, Universidad de Panamá, Panamá, 2008.

ZAMORANO, Abel. "El documento electrónico, su admisión y valor probatorio". En: Lex - Revista del Colegio Nacional de Abogados No.5 (ene.-ago. 1994), Panamá, 1994.

GONZÁLEZ J., Roberto. “Twitter un arma de doble filo. Las Redes sociales en el entorno laboral”. La Prensa Panamá, Año 30, Núm. 9925, P.2ª.

\section{Entrevistas}

PRADO, Eric Giovanni: Profesor Catedrático de Derecho Procesal Constitucional; Facultad de Derecho y Ciencias Políticas; Universidad de Panamá; "Admisibilidad de la evidencia electrónica, utilización de las redes sociales” (2013).

BERNAL, Miguel Antonio: Profesor Catedrático de Derecho Constitucional, Facultad de Derecho y Ciencias Políticas; Universidad de Panamá; "Derecho a la intimidad y redes sociales" (2013).

\section{Jurisprudencia Extrajera}

España. Tribunal Superior de Madrid. Sentencia de 23 de enero de 2012.

Argentina. Sala de lo Penal, Sección 1a, Sentencia de 17 Ene. 2012, $\mathrm{N}^{\circ}$ de Sentencia 2/2012 | N de Recurso: 8/2011.

\section{Leyes}

Panamá, Código Judicial, Libro Segundo Procedimiento Civil.

Panamá, ley 51 de 2008, Gaceta Oficial N²6090, publicada el 24 de julio de 2008. 


\section{Páginas de Internet}

FACEBOOK (2009). Politica de Privacidad de Facebook, Facebook Site Governance Notas [en línea], España. Recuperado el 11 de mayo de 2013, de: [https://www.facebook.com/note.php?note_id=+322317115300].

PONCE, Isabel (2012). Redes Sociales, Observatorio Tecnológico [en línea], España: Ministerio de Educación, Gobierno y Deportes. Recuperado el 10 de mayo de 2013, de: [http://recursostic.educacion.es/observatorio/web/es/ internet/web-20/1043-redes-sociales?start=1].

WIKIPEDIA (2013). Red Social, La enciclopedia libre [en línea], Fundación Wikimedia Inc. Recuperado el 6 de mayo de 2013 de: [http://es.wikipedia.org/ wiki/Red_social].

MINISTERIO DE EDUCACIÓN DE LA REPÚBLICA DE ARGENTINA [http://escritoriofamilias.educ.ar/datos/redes-sociales.html].

PEREDA CRISTINA. Recuperado en mayo de 2012 de [http://sociedad. elpais.com/sociedad/2012/01/27/actualidad/1327698056_548510.html].

BALLESTIN, Alberto (2014) [http://es.engadget.com/2014/03/22/ turquia-refuerza-censura-twitter-facebook-youtube/]

NOTUS. "Mata a su 'mejor amiga' de 65 puñaladas por subir fotos al Facebook". México, 2014. Recuperado de [http://notus.com.mx/mata-su-mejor-amiga-de-65-punaladas-por-subir-fotos-al-facebook/] 